УДК 582.681.81:581.45:543.544.5.068.7

\title{
ВАЛИДАЦИОННАЯ ОЦЕНКА МЕТОДИКИ ОПРЕДЕЛЕНИЯ РУТИНА В ЛИСТЬЯХ ИВЫ ТРЕХТЫЧИНКОВОЙ МЕТОДОМ ПЛАНАРНОЙ ХРОМАТОГРАФИИ
}

\author{
(C) Т.Д. Мезенова ${ }^{*}$ Е.Г. Санникова, А.Б. Дмитриев, О.И. Попова
}

\author{
Пятигорский медико-фрармацевтический институт - фрилиал ВолаГМУ \\ Минздрава России, ул. Калинина, 11, Пятигорск, 357500 (Россия), \\ e-mail: mezenova@yandex.ru
}

\begin{abstract}
Представлена валидированная методика идентификации и количественного определения рутина в листьях ивы трехтычинковой (Salix triandra L.) методом планарной тонкослойной хроматографии с денситометрической регистрацией аналитического сигнала.

Для эксперимента использовали спиртовое извлечение (спирт этиловый 70\%) из высушенных, предварительно обезжиренных хлороформом листьев ивы. Цифровую обработку хроматограмм проводили с помощью компьютерной программы «Видеоденситометр Sorbfil» (г. Краснодар).

Методика валидирована по следующим характеристикам: специфичность, чувствительность - предел обнаружения (ПО), предел количественного определения (ПКО), линейность, правильность, прецезионность.

Специфичность - окраска и $\mathrm{R}_{\mathrm{f}}$ пятен контрольного трека соответствует окраске и $\mathrm{R}_{\mathrm{f}}$ пятен стандартного образца $(0,63 \pm 0,02)$. Чувствительность: ПО =0,8 мкг; ПКО =2,4 мкг. Линейность - установлена линейная зависимость между количеством аналита и аналитическим сигналом - уравнение регрессии имеет вид: $\mathrm{S}=3,84 \cdot 10^{3} \mathrm{v}$; коэффициент корре-

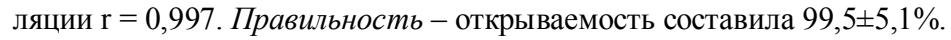

Определено содержание рутина в листьях ивы трехтычинковой, культивируемой в условиях Кавказских Минеральных Вод. Методику рекомендуется использовать для изучения химического состава и разработки норм качества на лекарственное сырье.

Ключевые слова: рутин, ива трехтычинковая Salix triandra L, идентификация, количественное определение, тонкослойная хроматография, «Видеоденситометр Sorbfil», валидация.
\end{abstract}

\section{Введение}

Ива трехтычинковая (Salix triandra L.) широко распространена на Северном Кавказе, относится к секции Amygdalinae. Рутин является специфичным для таксона данной секции ивы, содержание которого в листьях достигает 5\% [1]. Поскольку листья ивы трехтычинковой содержат значительное количество рутина и могут служить потенциальным сырьем для создания лекарственных средств на их основе, актуальной является разработка простой, доступной и эффективной методики анализа рутина в листьях ивы трехтычинковой.

Мезенова Татьяна Дмитриевна - кандидат фармацевтических наук, старший преподаватель кафедры аналитической химии,

e-mail: mezenova@yandex.ru

Санникова Евгения Геннадьевна - аспирант,

e-mail: dskompanceva@mail.ru

Дмитриев Александр Борисович - кандидат химических наук, доцент кафедры аналитической химии, e-mail: abdmitr2006@yandex.ru

Попова Ольга Ивановна - доктор фармацевтических наук, профессор кафедры фармакогнозии, e-mail: beegeeslover@mail.ru

\section{Эксиериментальная часть}

Сырьем для получения экстракта явились листья растения, культивируемого в условиях Кавказских Минеральных Вод в период 2010-2011 гг. Для эксперимента использовали спиртовое извлечение (спирт этиловый 70\%) из высушенных, предварительно обезжиренных хлороформом листьев ивы.

Приготовление раствора стандартного образца (СО) рутина: 0,1 г рутина (ФС 42-2508-96) (точная навеска) помещали в мерную колбу вместимо-

\footnotetext{
* Автор, с которым следует вести переписку.
} 
стью 100 мл, растворяли в спирте этиловом 95\% при нагревании на водяной бане. Раствор охлаждали до комнатной температуры и доводили спиртом до метки. Концентрация рутина в растворе 1,0 мкг/мкл.

Для идентификации и количественного определения использовали метод планарной тонкослойной хроматографии с денситометрической регистрацией аналитического сигнала. Хроматографирование проводили на пластинках марки Sorbfil ПТСХ-П-А-УФ (Краснодар) размером $10 \times 15$ см. В качестве подвижной фазы использовали систему н-бутанол - ледяная уксусная кислота - вода (4:1:1). Высота подъема растворителя 9 см. Детектирование проводили парами аммиака.

На линию старта хроматографической пластинки длиной 15 см наносили 1,0; 2,0; 3,0; 4,0; 5,0 мкл раствора СО (содержание рутина - 1,0; 2,0; 3,0; 4,0; 5,0 мкг соответственно). На этой же пластинке обозначали четыре линии контрольных треков, на которые наносили спиртовые извлечения из листьев ивы объемом 2,0; 3,0; 4,0; 5,0 мкл. Пробы наносили при помощи микрошприца МШ-10 (агат). Пластинки помещали в камеру для хроматографирования объемом $2000 \mathrm{~cm}^{3}$, насыщенную парами растворителя. После подъема растворителя на необходимый уровень пластинки вынимали, высушивали в вытяжном шкафу при комнатной температуре до удаления паров растворителя. На пластинке появляются пятна желтого цвета. Для усиления окраски пластинку держали над парами аммиака концентрированного.

Далее пластинки сканировали при помощи планшетного сканера HP Scanjet 3670 (разрешение $100 \mathrm{dpi)} \mathrm{и} \mathrm{осуществляли} \mathrm{их} \mathrm{цифровую} \mathrm{обработку} \mathrm{с} \mathrm{помощью} \mathrm{компьютерной} \mathrm{программы} \mathrm{«Видеоденсито-}$ метр Sorbfil» (Краснодар). Количественное определение проводили методом абсолютной калибровки (внешнего стандарта) по градуировочному графику зависимости «масса вещества - площадь пика» (линейная аппроксимация). Статистическая обработка результатов проводилась в соответствии с ОФС «Статистическая обработка результатов химического эксперимента и биологических испытаний» [2].

\section{Результаты и их обсуждение}

Согласно рекомендации ГФ ХІІІ и международных стандартов любая аналитическая методика должна быть подвергнута валидации, т.е. экспериментальному подтверждению ее пригодности к практическому использованию и получению достоверной информации об объекте анализа. Валидацию проводили по следующим характеристикам: специфичность, чувствительность - предел обнаружения (ПО), предел количественного определения (ПКО), линейность, правильность, прецезионность [3, 4].

Специфичность определяли по величине $\mathrm{R}_{\mathrm{f}}$ пятна контрольного трека, которое должно соответствовать $\mathrm{R}_{\mathrm{f}}$ пятен стандартного образца $(0,63 \pm 0,02)$. На треках контрольного образца визуально обнаруживалось пятно желтого цвета с $\mathrm{R}_{\mathrm{f}} 0,63$, что соответствует окраске и $\mathrm{R}_{\mathrm{f}}$ стандартных образцов (рис. 1). Эффективность пластинки около 2000 теоретических тарелок $(\mathrm{N})$.

Чувствительность: предел обнаружения (ПО) рассчитывали по формуле:

$$
\Pi \mathrm{O}=3,3 \cdot \mathrm{S}_{a} / \mathrm{b},
$$

где: $\mathrm{S}_{a}$ - стандартное отклонение свободного члена «а»; b - угловой коэффициент градуировочного графика $\mathrm{y}=\mathrm{a}+\mathrm{bx} . \Pi \mathrm{\Pi}=0,8$ мкг.

Предел количественного определения (ПКО) рассчитывали по формуле:

$$
\text { ПКО }=10 \cdot \mathrm{S}_{a} / \mathrm{b}, \text { ПКО = 2,4 мкг. }
$$

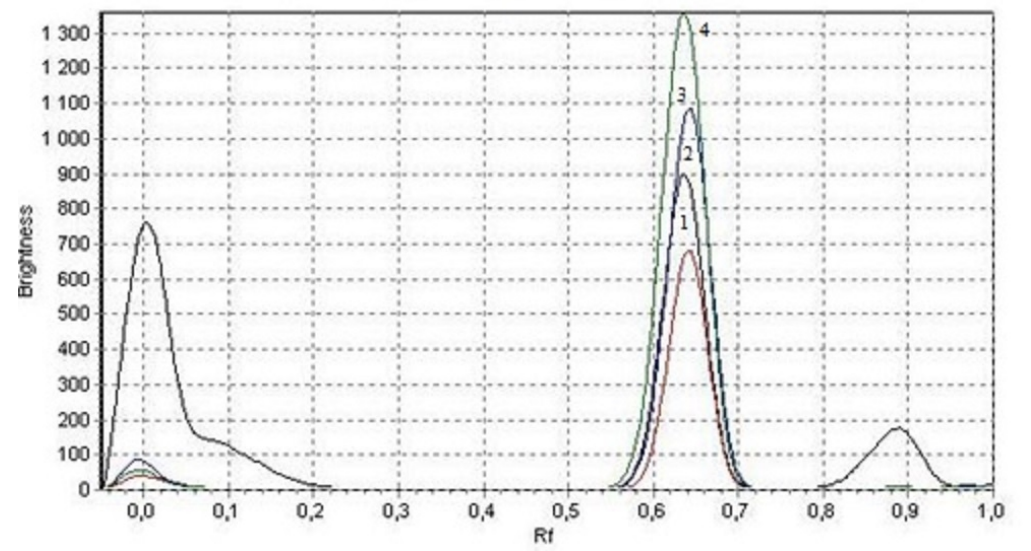

Рис. 1. Оцифрованная хроматограмма спиртового извлечения (2) и СО рутина (1 - 3 мкг/мкл; 3 - 4 мкг/мкл; 4 - 5 мкг/мкл) 
Линейность методики определяли экспериментально измерением аналитических сигналов для пяти проб с разными концентрациями СО рутина. Уравнение регрессии и коэффициент корреляции были рассчитаны в электронных таблицах Microsoft Excel. Методом наименьших квадратов определяли значимость свободного члена линейной зависимости (а) и углового коэффициента (b). Уравнение регрессии имеет вид: $\mathrm{S}=4,75 \cdot 10^{3} \mathrm{~m}$ (рис. 2).

Установлено, что зависимость площадей пиков от содержания рутина в аналитической области методики (от 1 до 5 мкг в пробе) является линейной (свободный член «а» значимо не отличается от нуля), коэффициент корреляции $\mathrm{r}=0,993$.

Также установлена линейная зависимость между различными объемами спиртового извлечения из листьев ивы, наносимого на пластинку, и аналитическим сигналом (рис. 3). Уравнение регрессии имеет вид: $\mathrm{S}=3,84 \cdot 10^{3} \mathrm{v}$. Коэффициент корреляции $\mathrm{r}=0,997$.

Правильность методики определяли методом «введено - найдено». По уравнению градуировочного графика рассчитывали содержание рутина на пяти уровнях концентраций СО и определяли метрологические характеристики (табл. 1).

Данной методикой было проведено количественное определение рутина в спиртовом извлечении из листьев ивы трехтычинковой. Результаты исследований приведены в таблице 2.

Содержание рутина в листьях ивы трехтычинковой составило $1,81 \pm 0,06 \%$ в пересчете на воздушносухое сырье и $1,91 \pm 0,06 \%$ - с учетом влажности сырья (5\%).

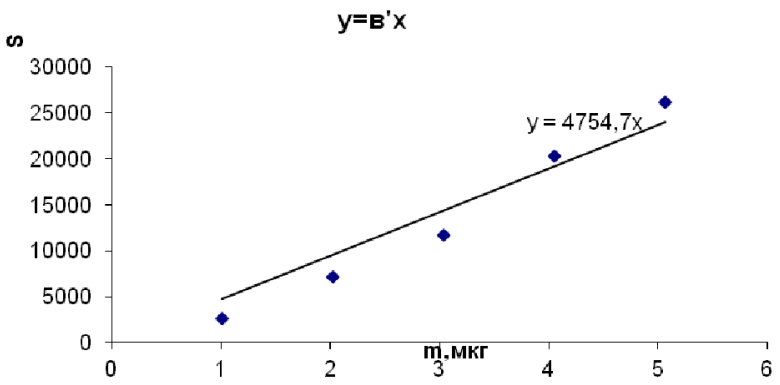

Рис. 2. Градуировочный график СО рутина

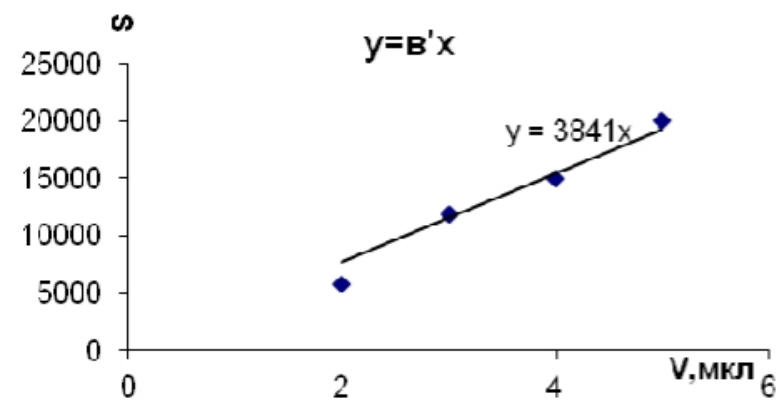

Рис. 3. График зависимости количества аналита и аналитического сигнала.

Таблица 1. Оценка правильности определения рутина

\begin{tabular}{c|c|c|c|c}
\hline Уровень & Взято, мкг & Найдено, мкг & Открываемость, $\%$ & Метрологические характеристики \\
\hline 1 & 1,0 & 0,98 & 98 & \\
1 & 1,0 & 0,93 & 93 & $\mathrm{Xcp}=99,5$ \\
2 & 2,0 & 1,92 & 96 & $\mathrm{SD}=2,2$ \\
2 & 2,0 & 2,14 & 107 & $\Delta \mathrm{X}=5,1$ \\
3 & 3,0 & 2,61 & 105 & $\mathrm{RSD}=7,1 \%$ \\
3 & 3,0 & 3,15 & 107 & $\mathrm{E} \%=5,1 \%$ \\
4 & 4,0 & 4,28 & 103 & \\
4 & 4,0 & 4,12 & 106 & \\
5 & 5,0 & 5,30 & 93 & \\
5 & 5,0 & 4,65 &
\end{tabular}

Таблица 2. Результаты определения содержания рутина в листьях ивы трехтычинковой. Оценка сходимости результатов

\begin{tabular}{c|c}
\hline Содержание, \% (возд. сух. сырье) & Метрологические характеристики \\
\hline 1,85 & $\mathrm{X}_{\mathrm{cp}}=1,81$ \\
1,82 & $\mathrm{SD}=0,02$ \\
1,86 & $\mathrm{RSD}^{2}=2,5 \%$ \\
1,77 & $\Delta \mathrm{X}=0,056$ \\
1,76 & $\mathrm{E}=3,12 \%$ \\
\hline
\end{tabular}




\section{Bbыводbl}

Полученные данные свидетельствуют о том, что методика специфична, имеет достаточно высокую чувствительность и эффективность. Методика количественного определения отвечает необходимым требованиям по показателям линейности, правильности и сходимости. Данную методику рекомендуется использовать для изучения химического состава и разработки норм качества на лекарственное сырье.

\section{Сиисок литературь}

1. Компанцев В.А. Химическое изучение фенольных гликозидов некоторых видов ив Северного Кавказа: дис. ... канд. фармацевт. наук. Пятигорск, 1970. 163 с.

2. Государственная фармакопея СССР. ХІ изд., вып. 1. М., 1987. С. 199-251.

3. Руководство ICN «Валидация аналитических методик». Содержание и методология // Фармация. 2008. №4. С. 3-10.

4. Государственная фармакопея СССР. ХІІІ изд. [Электронный ресурс]. URL: https://www.rosminzdrav.ru/ poleznye-resursy/gosudarstvennaya-farmakopeya-rossiyskoy-federatsii-xiii-izdaniya.

Поступило в редакцию 27 мая 2016 г.

После переработки 15 июня 2016 г.

Mezenova T.D.*, Sannikova E.G., Dmitriev A.B., Popova O.I. VALIDATION EVALUATION METHODS FOR DETERMINING RUTIN IN LEAVES OF WILLOW TRIANDRA BY METHOD PLANAR CHROMATOGRAPHY

Pyatigorsk Medical and Pharmaceutical Institute - a branch of Volgograd State Medical University, ul. Kalinina, 11, Pyatigorsk, 357500 (Russia), e-mail: mezenova@yandex.ru

Presents a validated method of identification and quantitative determination of rutin in the leaves triandra willow (Salix triandra L.) by planar thin-layer chromatography with densitometric registration of the analytical signal. For the experiment used an ethanolic extract (ethanol 70\%) from the dried, previously defatted with chloroform leaf willow.

Digital processing of the chromatograms was performed by using the computer program "Sorbfil Videodensitometer" (Krasnodar). The technique is validated by the following characteristics: specificity, sensitivity - limit of detection, the limit of quantification, linearity, trueness, precision.

Specificity - the color and rf of the spots of the control track corresponds to the color and $\mathrm{R}_{\mathrm{f}}$ of the spots of the standard sample $(0,63 \pm 0,02)$. Sensitivity: limit of detection $=0,8 \mu \mathrm{g}$; limit of quantification $=2,4 \mu \mathrm{g}$. Linearity - established linear relationship between amount of analyte and analytical signal - the regression equation has the form: $\mathrm{S}=3,84 \cdot 10^{3} \mathrm{v}$; correlation coefficient $r=0,997$. Trueness $-99,5 \pm 5,1 \%$

Determined the content of rutin in leaves of willow trentacinque, cultivated in the conditions of the Caucasian Mineral Waters. This technique is recommended for studies of chemical composition and development of quality standards for medicinal raw materials.

Keywords: rutin, willow triandra Salix triandra L, identification, quantitative determination, thin layer chromatography, "Videodensitometry Sorbfil", validation.

\section{References}

1. Kompantsev V.A. Khimicheskoe izuchenie fenol'nykh glikozidov nekotorykh vidov iv Severnogo Kavkaza: dis. ... kand. farmatsevt. nauk. [Chemical study of phenolic glycosides some species of willows of the North Caucasus: dis. ... Cand. pharmaceutical sciences]. Piatigorsk, 1970, 163 p. (in Russ.).

2. Gosudarstvennaia farmakopeia SSSR. [State Pharmacopoeia of the USSR]. vol. 1, Moscow, 1987, pp. 199-251. (in Russ.).

3. Farmatsiia, 2008, no. 4, pp. 3-10. (in Russ.).

4. Gosudarstvennaia farmakopeia SSSR. [State Pharmacopoeia of the USSR]. [Electronic resource], URL: https://www.rosminzdrav.ru/poleznye-resursy/gosudarstvennaya-farmakopeya-rossiyskoy-federatsii-xiii-izdaniya. (in Russ.).

\footnotetext{
* Corresponding author.
} 